Proc. Indian Acad. Sci. (Chem. Sci.), Vol. 112, No. 1, February 2000, pp. 51-61

(C) Indian Academy of Sciences

\title{
Hydrophobic interactions of phenoxazine modulators with bovine serum albumin
}

\author{
H N KALPANA ${ }^{\mathrm{a}}$, B C CHANNU ${ }^{\mathrm{a}}$, CHHABIL DASS ${ }^{\mathrm{b}}, \mathrm{P}^{\mathrm{J}} \mathrm{HOUGHTON}^{\mathrm{c}}$ \\ and $\mathrm{K}$ N THIMMAIAH ${ }^{\mathrm{a} *}$ \\ ${ }^{a}$ Department of Studies in Chemistry, University of Mysore, Manasagangotri, \\ Mysore 570 006, India \\ ${ }^{\mathrm{b}}$ Department of Chemistry, University of Memphis, Memphis, TN 38151, \\ USA \\ 'Department of Molecular Pharmacology, St. Jude Children's Research \\ Hospital, Memphis, TN 38105, USA
}

MS received 17 May 1999; revised 19 November 1999

\begin{abstract}
The interaction of 10-(3'-N-morpholinopropyl)phenoxazine [MPP], 10(4'-N-morpholinobutyl)phenoxazine [MBP], 10-(3'-N-morpholinopropyl)-2-chlorophenoxazine [MPCP], 10-(3'-N-piperidinopropyl)-2-chlorophenoxazine [PPCP] or 10-(3'-N-morpholinopropyl)-2-trifluoromethylphenoxazine [MPTP] with bovine serum albumin (BSA) has been studied by gel filtration and equilibrium dialysis methods. The binding of these modulators, based on dialysis experiments, has been characterized using the following parameters: percentage of bound drug $(\beta)$, the association constant $\left(K_{1}\right)$, the apparent binding constant $(k)$ and the free energy change $\left(\Delta F^{\circ}\right)$. The binding of phenoxazine derivatives to serum transporter protein, $\mathrm{BSA}$, is correlated with their octanol-water partition coefficient, $\log _{10} P$. In addition, effect of the displacing activities of hydroxyzine and acetylsalicylic acid on the binding of phenoxazine derivatives to albumin has been studied. Results of the displacement experiments show that phenoxazine benzene rings and tertiary amines attached to the side chain of the phenoxazine moiety are bound to a hydrophobic area on the albumin molecule.
\end{abstract}

Keywords. Phenoxazine; hydrophobic interaction; displacement experiments; bovine serum albumin.

\section{Introduction}

Investigation involving the binding of drugs to albumin has been described in numerous publications because of its pharmacokinetic importance ${ }^{1}$. In addition, the drug-albumin complex may be considered a model for gaining general fundamental insights into drugprotein binding. General rules of protein binding gained from this model could apply at least partially to the drug-receptor complex, provided that the receptor has a protein structure. Determination of the albumin binding of several structurally related compounds is a valuable tool for identifying those groups of a drug molecule that are involved in binding and for characterizing the binding forces concerned with the interaction of drugs with protein.

*For correspondence 
The binding of phenothiazine drugs to bovine serum albumin (BSA) has been studied ${ }^{1}$. Although most of the authors obtained total binding constants of the same order of magnitude, the number of binding sites varied considerably. It has been found ${ }^{2}$ that the number of binding sites on BSA for promazine and chlorpromazine changed with the concentration of the drugs, higher numbers being obtained at higher drug concentrations. These results suggest that phenothiazine derivatives are bound by hydrophobic interaction to the aromatic amino acids of the BSA molecule and that, under the influence of high drug concentrations, the number of available sites increase by swelling and unfolding of the BSA molecules in solution. Glasser and Krieglstein ${ }^{3}$ correlated the $\log _{10} P$ of some phenothiazine drugs and related compounds to their $\log (\beta / \alpha)$ values, $\beta$ and $\alpha$ being the fractions of bound drug and free drug respectively. A fairly good linear correlation $(r=0.969)$ for five 10-dimethylaminopropyl derivatives of phenothiazine was obtained. However, when other drugs were included, the correlation deteriorated.

Compounds of pharmacological interest have been found among phenoxazine derivatives $^{4}$ and have been claimed to be nervous system depressants, in particular with sedative, antiepileptic, tranquillising, spasmolytic, antitubercular and anthelmintic activities. Drug resistance has become a major obstacle in the clinical treatment of cancer as well as some microbial diseases. A variety of small molecules capable of modulating drug resistance has been prepared and examined. While a number of pharmacological agents have been shown to reverse drug resistance in vitro, there is still a need to identify more potent, more specific and less toxic modulators for clinical use. In an attempt to search for more potent and less toxic drug reversal agents, Thimmaiah et al ${ }^{5}$ have reported that the parent phenoxazine facilitated the uptake of vincristine (VCR) and vinblastine (VLB) in multidrug resistant (MDR) $\mathrm{GC}_{3} / \mathrm{c} 1$ and $\mathrm{KBCh}^{\mathrm{R}}-8-5$ cells to a greater extent than verapamil. In a subsequent study ${ }^{4,6}$, twenty $\mathrm{N}^{10}$-substituted phenoxazines were synthesized and examined for their ability to enhance the uptake of VLB and VCR in $\mathrm{GC}_{3} / \mathrm{cl}$ and $\mathrm{KBCh}^{\mathrm{R}}-8-5$ cells. Recently, Thimmaiah et $\mathrm{al}^{7}$ have demonstrated that 2chlorophenoxazines are able to partially reverse VLB resistance in MDR colon carcinoma cell line $\mathrm{GC}_{3} / \mathrm{cl}$ and completely reverse 86-fold $\mathrm{VLB}$ resistance in the MDR1 overexpressing breast carcinoma cell line BC 19/3. The same agents can partially sensitize BC 19/3 cells to taxol and doxorubicin, suggesting that the chlorophenoxazines show some specificity for modulating VLB resistance. The results show that substitution on the phenoxazine ring at position $\mathrm{N}^{10}$ is associated with an increase in antiproliferative and anti-MDR activities. Nevertheless, the exact mechanism of pharmacological action of phenoxazines remains unknown. Since these molecules are found to be useful as potential anti-MDR agents, studies have been undertaken to elucidate the nature of interactions with serum transporter protein, BSA.

\section{Experimental}

The synthesis and chemical characterization of MPP, MBP, MPCP, PPCP and MPTP have been carried out as per the literature ${ }^{4,8,9}$. The structures of the compounds are given in table 1.

Acetylsalicylic acid, bovine serum albumin and hydroxyzine were purchased from Sigma Chemical Company, USA. All chemicals were of reagent grade. All binding measurements were made in the presence of $0.02 \mathrm{M}$ phosphate buffer, $p \mathrm{H} 6 \cdot 8$, containing $0 \cdot 15 \mathrm{M} \mathrm{NaCl}$ and $3 \mathrm{mM}$ sodium thiosulphate ${ }^{1}$. Just before protein binding of a drug was 
Table 1. Name, molecular structure, molecular weight and $\log _{10} P$ values of the phenoxazine derivatives.

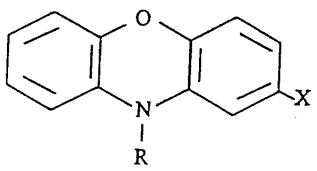

\begin{tabular}{|c|c|c|c|c|c|}
\hline $\begin{array}{l}\text { Com- } \\
\text { pound }\end{array}$ & Name & $\mathrm{R}$ & $X$ & MW & $\log _{10} P$ \\
\hline MPP & $\begin{array}{l}10-\left(3^{\prime} \text {-N-morpholinopropyl)- }\right. \\
\text { phenoxazine }\end{array}$ & $-\mathrm{CH}_{2}-\mathrm{CH}_{2}-\mathrm{CH}_{2}$ & $-\mathrm{H}$ & $346 \cdot 50$ & 1.48 \\
\hline MBP & $\begin{array}{l}10-\left(3^{\prime}-\mathrm{N} \text {-morpholinobutyl)- }\right. \\
\text { phenoxazine }\end{array}$ & $-\mathrm{CH}_{2}-\mathrm{CH}_{2}-\mathrm{CH}_{2}$ & $-\mathrm{H}$ & $360 \cdot 50$ & 1.72 \\
\hline MPCP & $\begin{array}{l}10-\left(3^{\prime}-\mathrm{N} \text {-morpholinopropyl)- }\right. \\
2 \text {-chlorophenoxazine }\end{array}$ & $-\mathrm{CH}_{2}-\mathrm{CH}_{2}=$ & $-\mathrm{Cl}$ & $381 \cdot 00$ & 1.90 \\
\hline РPCP & $\begin{array}{l}\text { 10-[4'-N-piperidinopropyl)- } \\
\text { 2- chlorophenoxazine }\end{array}$ & $-\mathrm{CH}_{2}-\mathrm{CH}_{2}-\mathrm{CH}$ & $-\mathrm{Cl}$ & 379.00 & $2 \cdot 40$ \\
\hline МРTP & $\begin{array}{l}\text { 10-(3'-N-morpholinopropyl)- } \\
\text { 2- trifluoromethylphenoxazine }\end{array}$ & $-\mathrm{CH}_{2}-\mathrm{CH}_{2}-\mathrm{CH}_{2}-$ & $-\mathrm{CF}_{3}$ & $414 \cdot 50$ & $2 \cdot 50$ \\
\hline
\end{tabular}

determined, the $p \mathrm{H}$ of the sample solution was measured and, wherever necessary, adjusted to $p \mathrm{H} 6 \cdot 8$ with $0 \cdot 1 \mathrm{~N} \mathrm{HCl}$ or $0 \cdot 1 \mathrm{~N} \mathrm{NaOH}$.

\subsection{Separation of phenoxazine-albumin complex by gel-filtration experiment}

Binding of phenoxazine derivatives to albumin was studied using gel filtration experiments. The experiments were performed on a $20 \times 1.3 \mathrm{~cm}$ column of sephadex ${ }^{\mathrm{R}} \mathrm{G}$ 50 fine (Pharmacia) at $22^{\circ} \mathrm{C}$, equilibrated with standard buffer solution. The flow rate was maintained at $25 \mathrm{ml} / \mathrm{h}$. BSA solution $(20 \mathrm{ml}, 1 \%)$ containing $1.0 \times 10^{-4} \mathrm{M}$ phenoxazine modulator, after incubation at $37^{\circ} \mathrm{C}$ for $6 \mathrm{~h}$, was loaded on to the column and washed with standard buffer. The effluent from the column was collected in fractions of $3 \mathrm{ml}$. Of these, $1.5 \mathrm{ml}$ each was used to determine protein concentration and the remaining $1.5 \mathrm{ml}$ for phenoxazine modulator estimation. Albumin content was determined by the 'biuret' method, while phenoxazine modulator was estimated colorimetrically after extracting with $n$-heptane in $50 \%$ sulphuric acid containing $10 \mathrm{mg} \% \mathrm{FeCl}_{3}$.

\subsection{Study of interaction of phenoxazines with BSA by equilibrium dialysis method}

Sample solution (20 ml) containing BSA (1\%) and one of the modulators (MPP, MBP, MPCP, PPCP or MPTP) in the concentration range $0 \cdot 1-5 \times 10^{-4} \mathrm{M}$ was taken in a $50 \mathrm{ml}$ centrifuge tube and incubated at $37^{\circ} \mathrm{C}$ for $6 \mathrm{~h}$ in a shaking water-bath incubator. Into each of four dialysis tubes ( $3 / 4$ " or $1.9 \mathrm{~cm}$ diameter), $5 \mathrm{ml}$ of the above reaction mixture was pipetted out. The dialysis tubes were then closed and immersed in a standard buffer solution taken in a measuring jar. The samples were dialysed for $12 \mathrm{~h}$ at $22^{\circ} \mathrm{C}$. At the end 
of the dialysis experiment, free phenoxazine modulator from the buffer medium was extracted into $n$-heptane. The organic layer was then evaporated and phenoxazine concentration measured calorimetrically using $4 \mathrm{ml}$ of $50 \%$ sulphuric acid containing $10 \mathrm{mg} \% \mathrm{FeCl}_{3}$.

\subsection{Displacement of phenoxazine modulator from BSA binding site by equilibrium dialysis}

The displacement of phenoxazines by hydroxyzine or acetylsalicylic acid was studied by means of equilibrium dialysis. In these experiments, binding of the phenoxazine modulator to BSA was determined after a displacing agent, either hydroxyzine or acetylsalicylic acid, was added to the incubation mixture.

\subsection{Measurement of lipophilicity}

Relative lipophilicity at $p \mathrm{H} \mathrm{7.2} \mathrm{of} \mathrm{each} \mathrm{of} \mathrm{the} \mathrm{compounds} \mathrm{used} \mathrm{in} \mathrm{this} \mathrm{study} \mathrm{was} \mathrm{assessed}$ using an adaptation of the method of Zamora $e t a l^{10}$. This method involves measuring the partitioning of modulator between 1-octanol and phosphate buffer solution (PBS) $(p \mathrm{H}$ 7.2). High pressure liquid chromatography (HPLC) grade 1-octanol was pre-saturated with aqueous phase buffer and, conversely, buffered aqueous phase was pre-saturated with HPLC grade 1-octanol before use. The modulator was dissolved in aqueous phase buffer/octanol at a final concentration of $1 \times 10^{-4} \mathrm{M}$, an equal volume of 1-octanol/buffer was added and the tubes were then continuously inverted for $15 \mathrm{~min}$ (experiments carried out over time intervals ranging from 5 to 60 min confirmed that equilibration was reached within $15 \mathrm{~min}$ ). The final concentration of modulator in both aqueous and octanol fractions was assessed by measuring the UV absorbance of these experimental fractions. The partition coefficient, $P$, was determined by dividing the concentration of modulator in the 1-octanol phase by the concentration in the aqueous phase. $\log _{10} P$ was used as a measure of lipophilicity.

\section{Results and discussion}

\subsection{Evaluation of binding parameters}

The binding of phenoxazine modulators (MPP, MBP, MPCP, PPCP and MPTP) to BSA, based on dialysis experiments, was characterized by the parameters, percentage of bound modulator $(\beta)$, association constant $\left(K_{1}\right)$, apparent binding constant $(k)$ and free energy change $\left(\Delta F^{\circ}\right)$ (table 2$)$. The symbols, dimensions and methods of analysis of the values used to characterize the protein binding and the hydrophobic character of the modulators are summarized in table 3. Results of the gel filtration experiment show that the bound phenoxazine modulator moves with the velocity of BSA. When experiments were performed in series for one substance, only the fractions after the protein zone have been assayed for phenoxazine modulator.

The effect of concentration of phenoxazine modulator (MPP, MBP, MPCP, PPCP or MPTP) on the binding to BSA was studied by dialysis experiments. In these studies, concentrations of the modulator were varied in the range $0.1-5 \times 10^{-4} \mathrm{M}$, keeping the protein concentration constant (1\%). The data obtained are shown in figure 1 . Examination of the data shows that binding increases with increasing concentration of 
phenoxazine at low modulator/protein ratios. The amount of free drug remains the same in spite of the fact that the concentration of the modulator is further increased (figure 1), thereby suggesting more binding sites on BSA, an observation similar to that made in the case of binding of phenothiazines to $\mathrm{BSA}^{1}$. The apparent binding constant $k$ and regression coefficient $m$ were calculated by plotting concentration of free-phenoxazine modulator vs. concentration of bound-phenoxazine modulator (figure 2). In order to calculate the total binding constant, $K_{1}$, the Scatchard plot for the binding of the

Table 2. Binding of several phenoxazine derivatives to bovine serum albumin.

\begin{tabular}{|c|c|c|c|c|c|c|}
\hline $\begin{array}{l}\text { Phenoxazine } \\
\text { derivative }\end{array}$ & $\begin{array}{l}\text { Percentage } \\
\text { of bound } \\
\text { drug } \\
(\beta)^{\mathrm{a}}\end{array}$ & $\begin{array}{l}\text { Regression } \\
\text { coefficient } \\
\quad(m)^{b}\end{array}$ & $\begin{array}{l}\text { Apparent } \\
\text { binding } \\
\text { constant } \\
\quad(k)\end{array}$ & $\begin{array}{c}\text { Associated } \\
\text { constant } \\
K_{1} \times 10^{-4} \\
\left(\mathrm{M}^{-1}\right)^{\mathrm{c}}\end{array}$ & 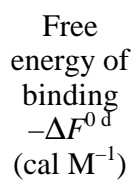 & $\log (\beta / \alpha)$ \\
\hline $\begin{array}{l}\text { 10-(3'-N-morpholinopropyl)- } \\
\text { phenoxazine (MPP) }\end{array}$ & 31.78 & $0 \cdot 38$ & 0.48 & $1 \cdot 3$ & 5553 & $-0 \cdot 3317$ \\
\hline $\begin{array}{l}\text { 10-(3'-N-morpholinobutyl)- } \\
\text { phenoxazine (MBP) }\end{array}$ & $54 \cdot 40$ & $1 \cdot 11$ & $1 \cdot 28$ & $3 \cdot 1$ & 6063 & 0.0766 \\
\hline $\begin{array}{l}\text { 10-(3'-N-morpholinopropyl)- } \\
\text { 2-chlorophenoxazine (MPCP) }\end{array}$ & $66 \cdot 64$ & 1.73 & 1.99 & $4 \cdot 2$ & 6241 & $0 \cdot 3005$ \\
\hline $\begin{array}{l}\text { 10-(3'-N-piperidinopropyl)- } \\
\text { 2-chlorophenoxazine (PPCP) }\end{array}$ & 77.68 & $3 \cdot 29$ & 3.99 & $9 \cdot 9$ & 6701 & $0 \cdot 5416$ \\
\hline $\begin{array}{l}\text { 10-(3'-N-morpholinopropyl)- } \\
\text { 2-trifluoromethyl phenoxazine } \\
\text { (MPTP) }\end{array}$ & e 73.60 & $2 \cdot 58$ & $2 \cdot 91$ & $5 \cdot 8$ & 6430 & 0.4453 \\
\hline
\end{tabular}

${ }^{\mathrm{a}} \beta$ is the percentage of bound drug in a $1 \%$ BSA solution with a total concentration $c=10^{-4} \mathrm{M}$ of phenoxazine modulator

${ }^{5} m$, the regression coefficient and $k$, the apparent binding constant, were obtained from figure 2, see also table 3

${ }^{\mathrm{c}} K_{1}$ is the association constant obtained from the Scatchard plot (figure 3)

${ }^{\mathrm{d}} \Delta F^{\circ}$ is the free binding energy calculated from $-R T \ln K$

Table 3. Symbols, dimensions and methods of analysis of the parameters used.

\begin{tabular}{lccl}
\hline Parameter* & Symbol & Dimension & \multicolumn{1}{c}{ Method of analysis } \\
\hline Total conc. of deriv. & $c$ & $\mathrm{M}$ & By weight, colourimetry \\
Conc. of free deriv. & $c_{f}$ & $\mathrm{M}$ & Gel filtration, dialysis \\
Conc. of bound deriv. & $c_{b}$ & $\mathrm{M}$ & $c_{b}=c-c_{f}$ \\
Conc. of albumin & $c_{a}$ & $\mathrm{~g} / 100 \mathrm{ml}$ & By weight, biuret method \\
Percent. of free deriv. & $\alpha$ & $\%$ & Gel filtration, dialysis \\
Percent. of bound deriv. & $\beta$ & $\%$ & $\beta=100-\alpha$ \\
Sp. binding capacity & $\bar{r}$ & $\mathrm{M} / \mathrm{M}$ & $\bar{r}=c_{b} / c_{a}$ in moles \\
Regression coeff. & $m$ & - & Figure 2 \\
Appar. binding const. & $k$ & - & $k=c_{b} / c_{f}$ (figure 2) \\
Assoc. const. & $K_{1}$ & $10^{4} \mathrm{M}^{-1}$ & Scatchard plot (figure 3) \\
Free binding energy & $\Delta F^{\circ}$ & $\mathrm{Cal} / \mathrm{M}$ & $\Delta F^{\circ}=-R T$ In $K_{1}$ \\
Partition coeff. & $P$ & $\mathrm{M} / \mathrm{M}$ & Partition between $n$-octanol and \\
& & & buffer solution, $p \mathrm{H} 7 \cdot 2$ \\
\hline
\end{tabular}

*Abbreviations: Conc. - concentration; deriv. - derivative; percent. - percentage; sp. - specific; coeff. - coefficient; appar. - apparent; assoc. - association; const. - constant. 


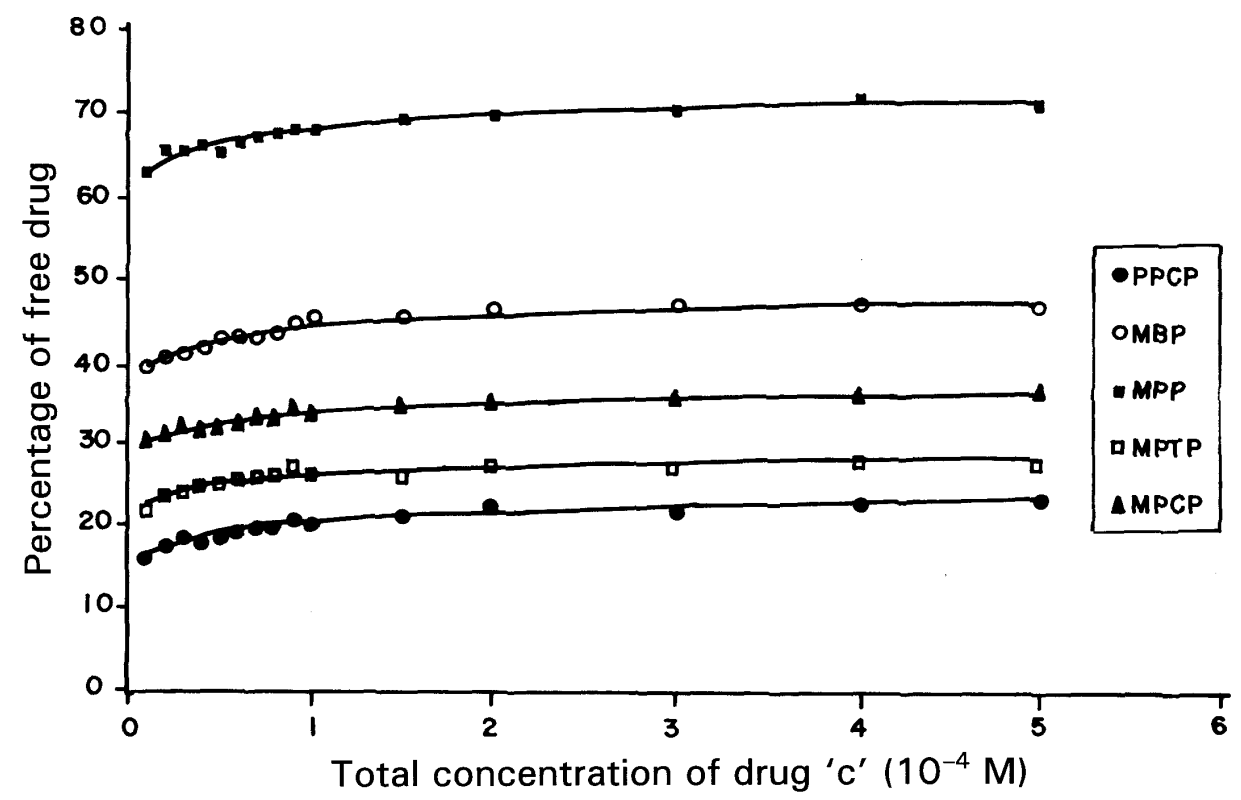

Figure 1. Binding of varying concentrations of the phenoxazine modulators to bovine serum albumin. Plots of percentage of free phenoxazine derivative versus total concentration of phenoxazine derivative $\left(10^{-4} \mathrm{M}\right)$. Binding measurements were carried out in a $1 \%$ BSA solution $\left(p \mathrm{H} 6 \cdot 8,22^{\circ} \mathrm{C}\right.$, incubated at $37^{\circ} \mathrm{C}$ for $\left.6 \mathrm{~h}\right)$. Each point represents the mean value of two experiments.

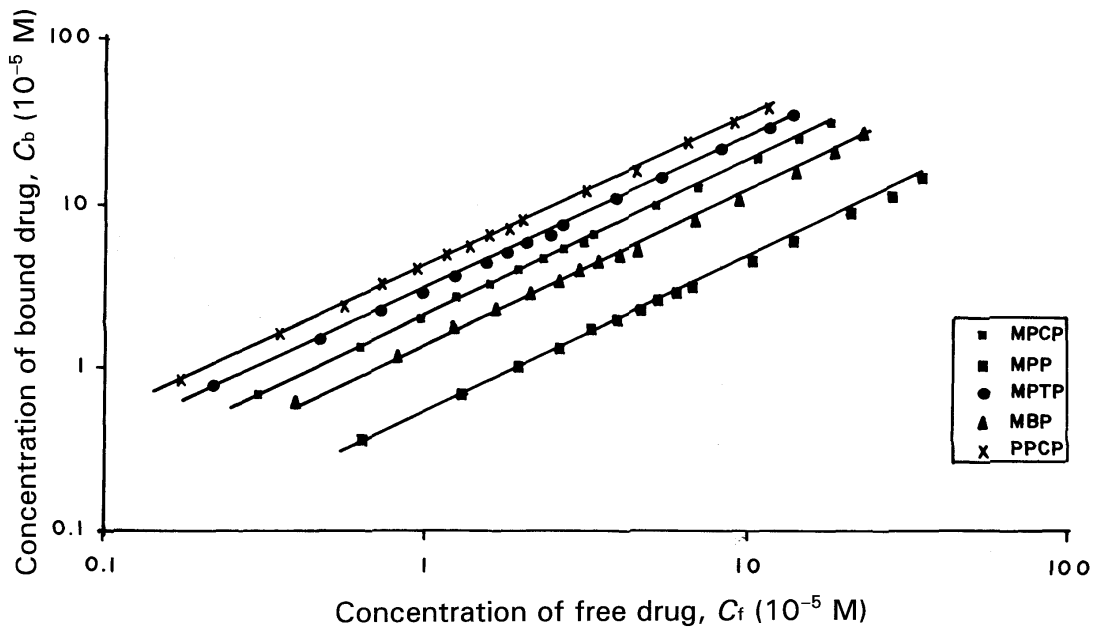

Figure 2. Binding capacity of a $1 \%$ albumin solution for phenoxazine derivatives. Plots of concentration $C_{b}$ of bound phenoxazine derivative $\left(0.1 \times 10^{-5}\right.$ to $\left.100 \times 10^{-5} \mathrm{M}\right)$ vs. concentration of free phenoxazine derivative $\left(0.1 \times 10^{-5}\right.$ to $\left.100 \times 10^{-5} \mathrm{M}\right)$. Binding measurements were carried out in $1 \%$ BSA solution $(p \mathrm{H} 6.8$, $22^{\circ} \mathrm{C}$, incubated at $37^{\circ} \mathrm{C}$ for $6 \mathrm{~h}$ ). Each point represents a single experiment. Here we obtain the binding constants $m$ and $k$, see also table 2. For statistical data see table 4 . 


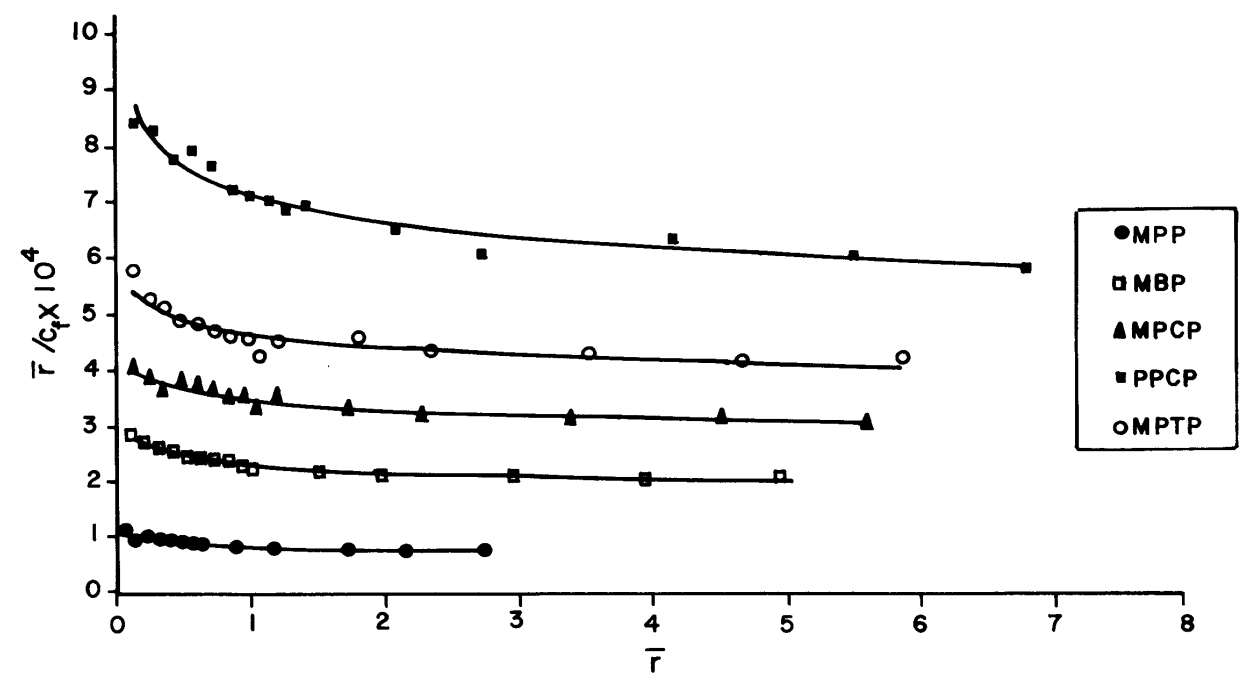

Figure 3. Scatchard plot of the binding of the phenoxazine derivatives to bovine serum albumin. $\bar{r} / c_{f}$ in $10^{-4} \mathrm{M}^{-1}$ vs. number of moles of phenoxazine per mole of albumin $(\bar{r})$. All measurements were made in $1 \%$ albumin solution $\left(p \mathrm{H}=6 \cdot 8,22^{\circ} \mathrm{C}\right)$. Each point represents the mean value of two single experiments. For total binding constant $K_{1}$ see table 2 .

Table 4. Statistical data for the binding of varying concentrations of phenoxazine derivatives with bovine serum albumin.

In all the cases, the number of experiments $=26$

\begin{tabular}{lccc}
\hline Derivative & $\begin{array}{c}\text { Equation of the regression line } \\
\text { in the double logarithmic system }\end{array}$ & Correl. coeff. $(r)$ & Significance of $r$ \\
\hline MPP & $y=0.0414+0.38 \mathrm{x}$ & 0.9970 & Significant \\
MBP & $y=0.0434+1.11 \mathrm{x}$ & 0.9890 & Significant \\
MPCP & $y=0.0568+1.73 \mathrm{x}$ & 0.9990 & Significant \\
PPCP & $y=0.0900+3.20 \mathrm{x}$ & 0.9980 & Significant \\
MPTP & $y=0.0443+2.58 \mathrm{x}$ & 0.9990 & Significant \\
\hline
\end{tabular}

Abbreviations: Correl. - correlation; coeff. - coefficient

Table 5. Statistical data for the displacement of phenoxazine derivatives from their albumin binding sites by hydroxyzine.

Number of parallel experiments in each case $=20$

\begin{tabular}{lccc}
\hline $\begin{array}{l}\text { Phenoxazine } \\
\text { deriv. }\end{array}$ & $\begin{array}{c}\text { Eqn. of the regression } \\
\text { line } y=\end{array}$ & $\begin{array}{c}\text { Correlation } \\
\text { coefficient }(r)\end{array}$ & $\begin{array}{c}\text { Significance } \\
\text { of } r\end{array}$ \\
\hline MPP + Hyd. & $65 \cdot 93+0 \cdot 263 \mathrm{x}$ & 0.9183 & $\begin{array}{l}\text { Significant } \\
\text { Significant }\end{array}$ \\
MBP + Hyd. & $46 \cdot 39+0 \cdot 305 \mathrm{x}$ & 0.9761 & Significant \\
MPCP + Hyd. & $28 \cdot 39+0 \cdot 355 \mathrm{x}$ & 0.8930 & Significant \\
PPCP + Hyd. & $20 \cdot 02+0 \cdot 483 \mathrm{x}$ & 0.9902 & Significant \\
MPTP + Hyd. & $25 \cdot 26+0 \cdot 200 \mathrm{x}$ & 0.9619 & \\
\hline
\end{tabular}

Abbreviations: Deriv. - derivative; eqn. - equation; Hyd. - hydroxyzine 
phenoxazine modulators to BSA was obtained (figure 3). Comparison of the $k$ and $K_{1}$ values within the compounds examined, showed that the modulators bind to BSA in the order: $\mathrm{PPCP}>\mathrm{MPTP}>\mathrm{MPCP}>\mathrm{MBP}>\mathrm{MPP}$, indicating that phenoxazines containing $-\mathrm{CF}_{3}$ or $-\mathrm{Cl}$ in position $\mathrm{C}-2$ have greater affinity to the protein than those containing $-\mathrm{H}$ in that position. Binding of these compounds to BSA was supported by $\Delta F^{\circ}$ values (table 2 ). Further, the compounds at $\mathrm{IC}_{10}$ were examined for their ability to modulate the cytotoxicity of VLB against $\mathrm{KBCh}^{\mathrm{R}}-8-5$ cells and the data shows that anti-MDR activity increases in the order PPCP $>$ MPTP $\approx$ MPCP $>$ MBP $>\mathrm{MPP}^{4,6-9}$. This rank order is the same as for the binding efficiency of these compounds with BSA.

\subsection{Relationship between bovine serum albumin binding and hydrophobic character of phenoxazine modulators}

Several authors have demonstrated a correlation between the hydrophobic character and protein binding of low molecular weight substances ${ }^{11-15}$. These results suggest that hydrophobic interactions play an important role in protein binding of organic compounds. However, a good correlation between protein binding and partition coefficients can be shown only for substances of structurally related groups. Hence, not only can hydrophobic interactions be present in protein binding of organic molecules, but also other binding mechanisms such as ionic binding, hydrogen binding or steric effects, etc. must be also involved ${ }^{16}$.

The hydrophobic character of phenoxazine modulators $\left(\log _{10} P\right)$ was determined (table 1) to look for a possible quantitative correlation between the lipid solubility of these compounds and their protein binding ability. Analysis of the relationship between lipid

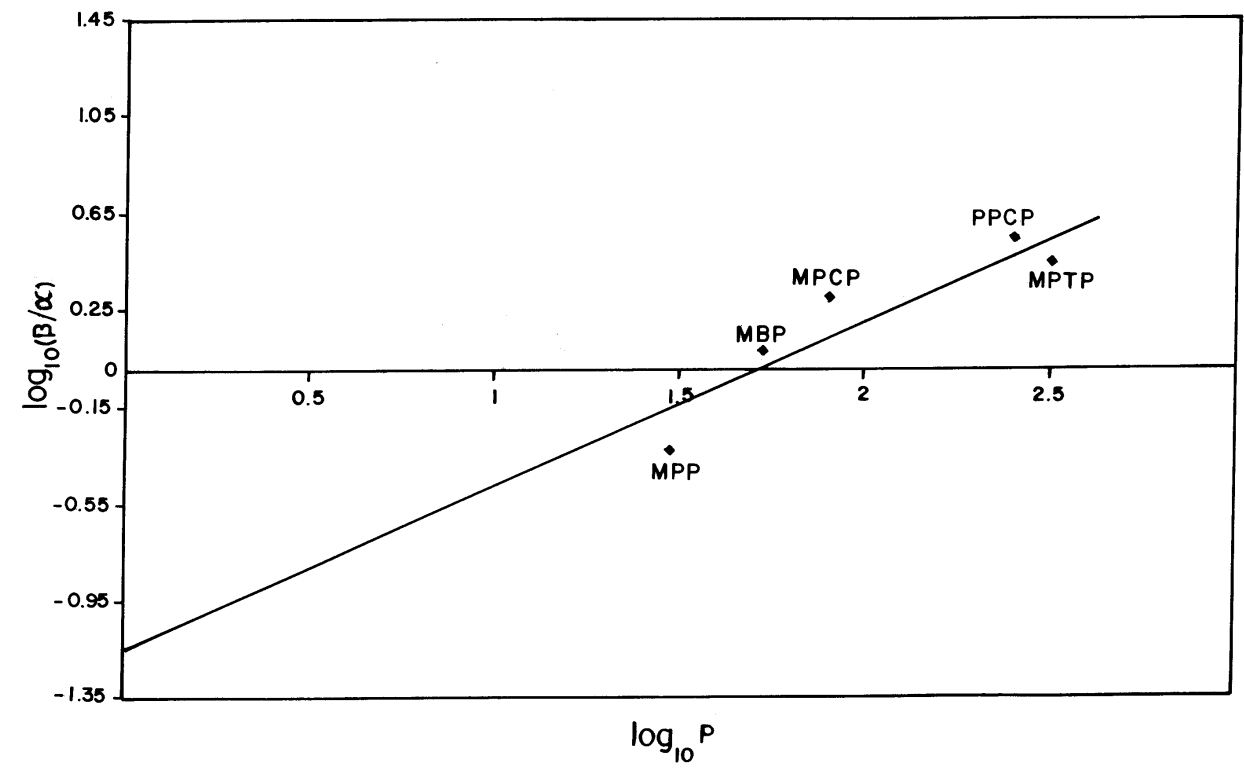

Figure 4. Relation between albumin binding and partition coefficients of phenoxazine derivatives. $\log (\beta / \alpha)$ vs. $\log _{10} P$. The equation of the regression line is $\log (\beta / \alpha)=-1.251+0.729 \log _{10} P$. 


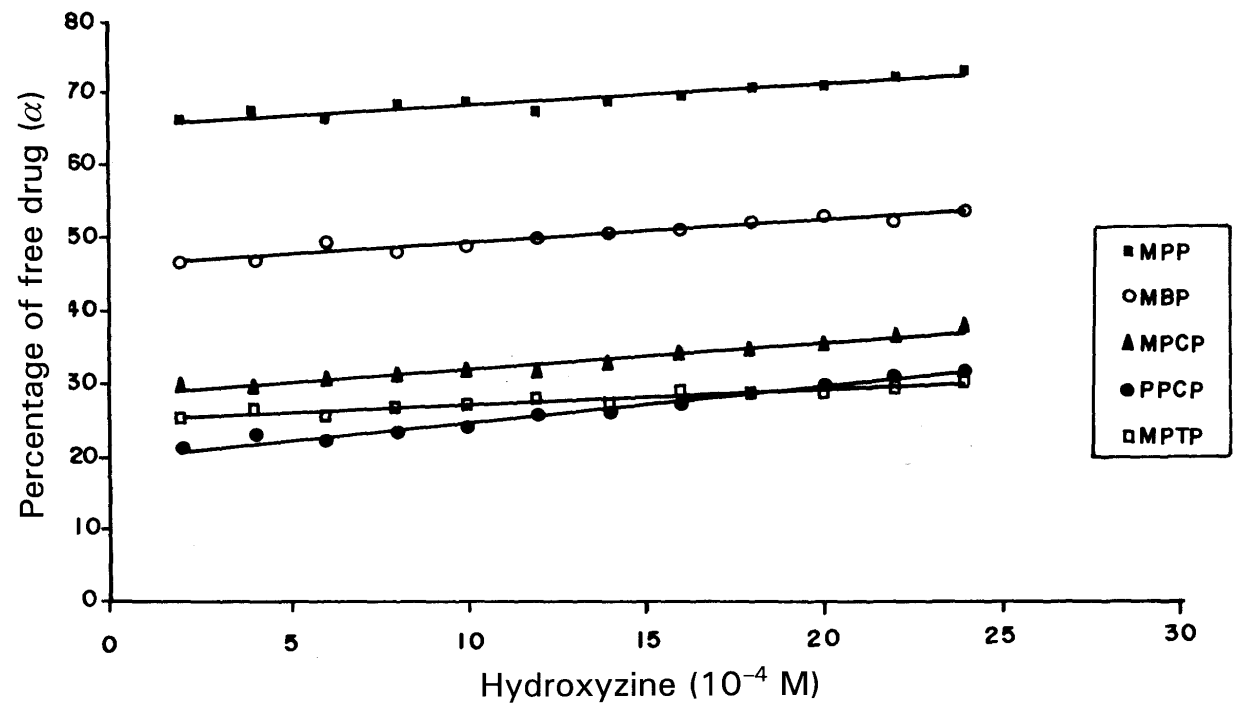

Figure 5. Influence of hydroxyzine on the binding of phenoxazine derivatives to bovine serum albumin. Percentage of free phenoxazine derivative in the albumin solution vs. total concentration of hydroxyzine $\left(10^{-4} \mathrm{M}\right)$. All measurements were made in $1 \%$ albumin solution containing $10^{-4} \mathrm{M}$, phenoxazine derivative and varying concentrations of hydroxyzine. Each point represents the mean value of two single experiments. For statistical evaluations see table 5.

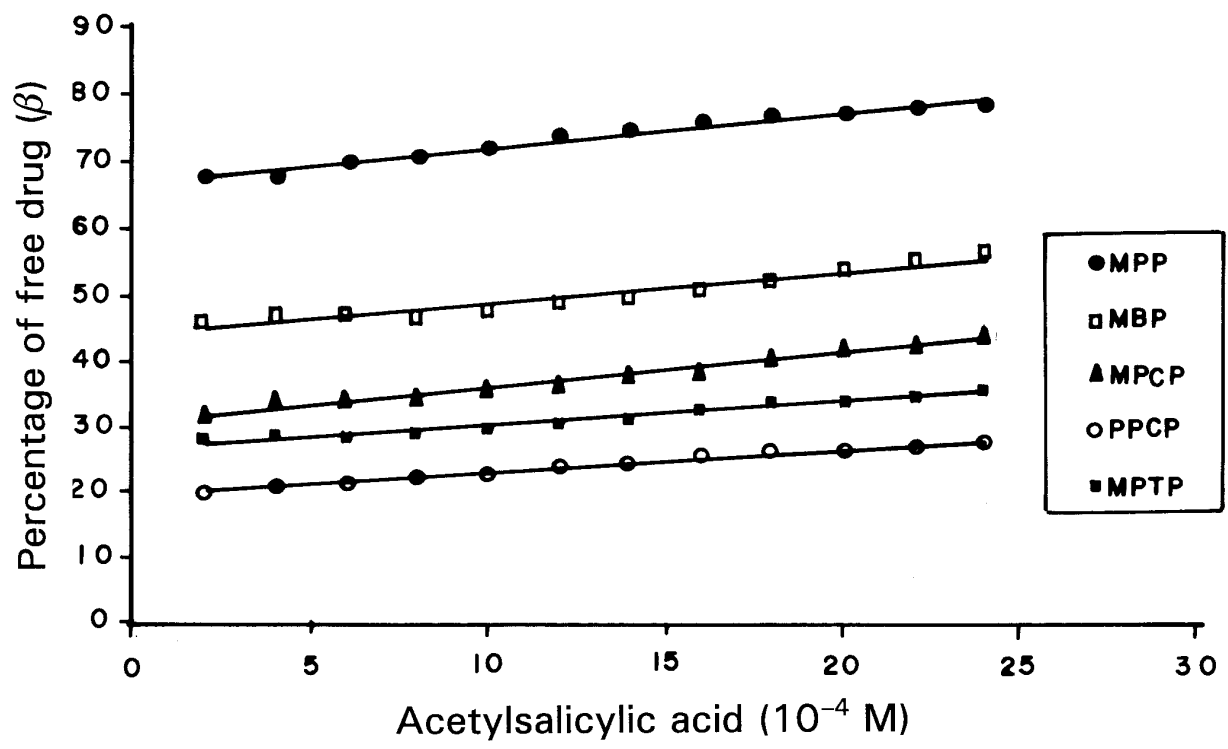

Figure 6. Displacement of phenoxazine derivatives by acetylsalicylic acid from binding to bovine serum albumin. Percentage of free phenoxazine derivative vs. total concentration of acetylsalicylic acid $\left(10^{-4} \mathrm{M}\right)$. All measurements were made in a $1 \%$ albumin solution containing one of the phenoxazine derivatives $10^{-4} \mathrm{M}$ and varying concentrations of acetylsalicylic acid. Each point represents the mean value of two single experiments. 
solubility of modulators used in this study and the fraction, $\log (\beta / \alpha)$, where $\beta$ is the percentage of bound phenoxazine and $\alpha$ is the percentage of free phenoxazine modulator showed a good correlation (figure 4). $(\beta / \alpha)$ function is preferred for this type of correlation because it is directly analogous to the organic solvent-buffer partition coefficient. The following equation was arrived at from the $\log (\beta / \alpha)$ and $\log _{10} P$ data for five phenoxazine derivatives substituted in position C-2 of the phenoxazine nucleus: log $(\beta / \alpha)=-1.251+0.729 \log _{10} P$ (correlation coefficient $r=0.91784$ ). For the five phenoxazine modulators, hydrophobicity decreased in the order: MPTP > PPCP > MPCP $>\mathrm{MBP}>\mathrm{MPP}$. Hence, it is apparent from these results that the BSA binding of the phenoxazine derivatives with substituents in position C-2 of the phenoxazine nucleus increases with their hydrophobic character.

\subsection{Displacement of phenoxazine modulators from their bovine serum albumin binding sites}

Simple aromatic substances like benzoic acid or aniline are able to displace phenothiazines from their binding sites on the albumin molecule ${ }^{17,18}$. In order to understand the BSA binding moieties of the phenoxazine modulators (MPP, MBP, MPCP, PPCP and MPTP), the authors have studied the displacement experiments by the dialysis method using hydroxyzine and acetylsalicylic acid. In these experiments, the binding of the phenoxazine modulators to BSA was determined after the displacing agent, hydroxyzine or acetylsalicylic acid, was added to the incubation mixture.

Participation of the side chain in the total binding of phenoxazine derivatives is indicated in displacement experiments with hydroxyzine and the data are shown in figure 5. Examination of the data shows that hydroxyzine displaces MPTP, MPP and MBP by about $5-6 \%$ and PPCP and MPCP by about $10-12 \%$ from their BSA binding sites. This might be explained by assuming that the aliphatic side chain between the $\mathrm{N}^{10}$ - of the phenoxazine nucleus and the nitrogen atom of the side-chain tertiary amine is not in a position to contribute significantly to the binding of the phenoxazine modulators used.

Acetylsalicylic acid competes with the benzene rings of the phenothiazine ring system for binding to BSA ${ }^{1}$. Since acetylsalicylic acid competes with the phenothiazine ring system for binding to BSA, the authors have examined the effect of acetylsalicylic acid as displacing agent to determine whether the benzene rings of phenoxazine modulator are involved in binding to BSA. These experimental data are shown in figure 6. Examination of the data from figure 6 has highlighted that acetylsalicylic acid displaces phenoxazine modulators (PPCP and MPTP by 6-7\%, MPCP, MBP and MPP by 9-10\%) from their BSA binding sites.

In summary, the results of the investigation suggest that phenoxazines are bound to albumin possibly by hydrophobic interactions.

\section{Acknowledgements}

HNK thanks the Department of Science and Technology, Government of India, New Delhi for a fellowship and Mysore University.

\section{References}

1. Krieglstein J, Meiler W and Staab J 1972 Biochem. Pharmacol. 21985 
2. Hulshoff A and Perrin J H 1977 J. Med. Chem. 20430

3. Glasser H and Krieglstein J 1970 Naunyn-Schmiedebergs Arch. Pharmakol. 265331

4. Thimmaiah K N, Horton J K, Seshadri R, Israel M, Houghton J A, Harwood F C and Houghton P J 1992 J. Med. Chem. 353358

5. Thimmaiah K N, Horton J K, Qian X D, Beck W T, Houghton J A and Houghton P J 1990 Cancer Commun. 2249

6. Horton J K, Thimmaiah K N, Harwood F C, Kuttesh J D and Houghton P J 1993 Mol. Pharmacol. 44552

7. Thimmaiah K N, Jayashree B S, Germain G S, Houghton P J and Horton J K 1998 Oncol. Res. 1029

8. Eregowda G B, Kalpana H N, Hegde R and Thimmaiah K N Indian J. Chem. B (in press).

9. Eregowda G B, Krishnegowda G, Kalpana H N, Channu B C, Dass C, Horton J K, Houghton P J and Thimmaiah K N 1999 Asian J. Chem. 11878

10. Zamora J M, Pearce H L and Beck W T 1988 Mol. Pharmacol. 33454

11. Bird A E and Marshall A C 1967 Biochem. Pharmacol. 162275

12. Hansch C 1968 J. Med. Chem. 11920

13. Hansch C and Fujita T 1964 J. Am. Chem. Soc. 861616

14. Hansch C, Kiehs K and Lawrence G L 1965 J. Am. Chem. Soc. 875770

15. Scholtan W, Schlossmann K and Rosenkranz H 1968 Arzneimitted-Forsch. 18767

16. Kauzmann W 1959 Adv. Protein Chem. 141

17. Girard A 1962 US Patent 3 048, 586; 1963 Chem. Abstr. 58 147lg

18. Franz J W, Jahnchen E and Krieglstein J 1969 Naunyn-Schmiedebergs Arch. Pharmakol. 264 462 